\title{
Acréscimos, ao invés de supressões: reflexões pedagógicas sobre as representações na formação de arquitetos
}

\author{
Artur Simöes Rozestraten
}

Professor Associado FAUUSP, São Paulo

Contato: artur.rozestraten@gmail.com

\section{RESUMO}

A partir dos conceitos de sistema aberto, sistema fechado e das possibilidades de combinaçóes híbridas entre tais extremos, este artigo apresenta reflexóes sobre a natureza das representaçôes gráficas e tridimensionais, considerando potências, limitações e interaçóes complementares entre diferentes representaçóes. Em seguida, o texto apresenta consideraçóes sobre aspectos conceituais do desenhar, sobre aspectos da história do desenho e analisa suas confluências para o digital. São analisadas, então, algumas características do digital, do ponto de vista tecnológico, reconhecendo tanto o fechamento do sistema quanto as aberturas recentes para interaçôes complementares com outras representaçóes. Para concluir, experiências educacionais recentes realizadas na FAUUSP são apresentadas e formulam-se algumas questôes que pretendem estimular o debate e o aprofundamento de reflexôes críticas sobre o tema.

Palavras-chave: Representaçôes; Modelagem tridimensional; Desenho

\section{ABSTRACT}

Beginning with the concepts of open, closed and hybrid systems, this article presents reflections on the nature of graphical and threedimensional representations, considering potentials, limitations and complementary interactions between different representations. After that, the text presents considerations on conceptual aspects of drawing, some aspects of the history of drawing and analyzes its confluences with the digital. Some characteristics of the digital, from a technological point of view, are analyzed, recognizing both the closing of the system and the recent openings for complementary interactions with other representations. To conclude, recent educational experiences at FAUUSP are presented and some questions are formulated intending to encourage the debate and the deepening of critical reflections on the subject.

Key-words: Representations; Three-dimensional modeling; Drawing. 


\section{Introduçáo}

No campo da modelagem tridimensional, que em sentido muito abrangente compreende a construção de objetos - não apenas como modelos, maquetes e protótipos na Arquitetura, no Urbanismo e no Design -, é possível reconhecer, de início, duas ordens de sistemas construtivos opostos que, conjugados experimentalmente entre si, podem vir a compor infinitas variações híbridas originais.

O universo dos brinquedos "de construção", nomeados em inglês building toys ou building sets, tendo o LEGO como exemplo bastante conhecido, pode apresentar as características principais dos sistemas construtivos fechados, isto é, sistemas com conjuntos normatizados de peças pré-definidas, moduladas, que se encaixam perfeitamente entre si e, justamente por isso, tendem a ser excludentes, pois se fecham a interaçôes com peças e materiais não-padronizados, externos ao sistema.

No extremo oposto estariam os sistemas construtivos abertos que podem ter como referência o que Lévi-Strauss (1908-2009) definiu em seu "Pensamento Selvagem" (1962) como base das açôes de bricolagem $^{1}$, ou seja, um campo de possibilidades, mais do que um sistema, propriamente, sem peças pré-definidas que se vale de múltiplas técnicas e materiais circunstanciais - ditos também "de ocasião" - e que, portanto, tendem a ser inclusivos, na medida em que dependem de abertura a tudo o que se tem disponível à mão, em um determinado momento e lugar.

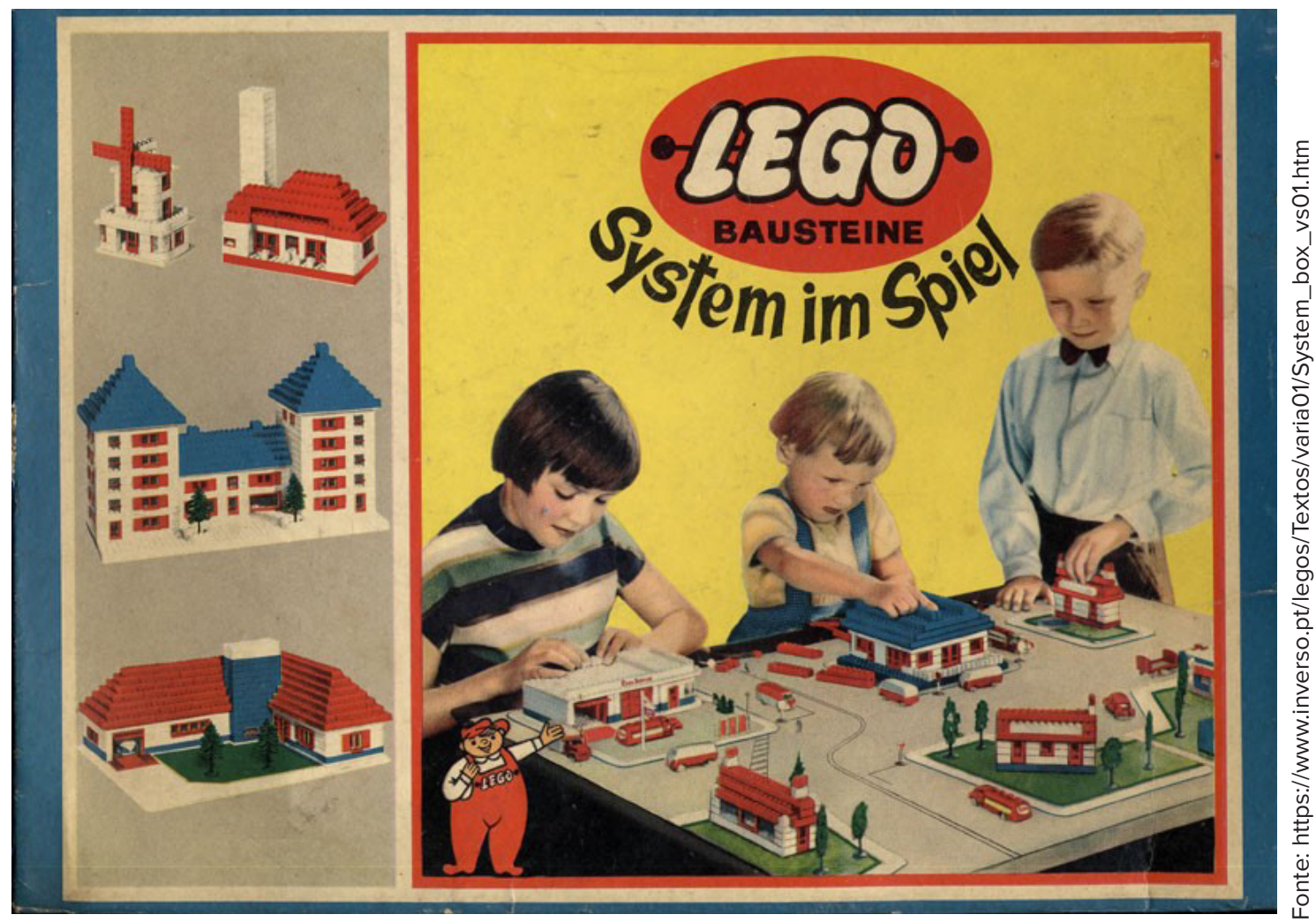

Figura 1: Caixa com conjunto de peças LEGO, 1956/1957.

Revista online do Departamento de Arquitetura e Urbanismo da Pontifícia Universidade Católica - 


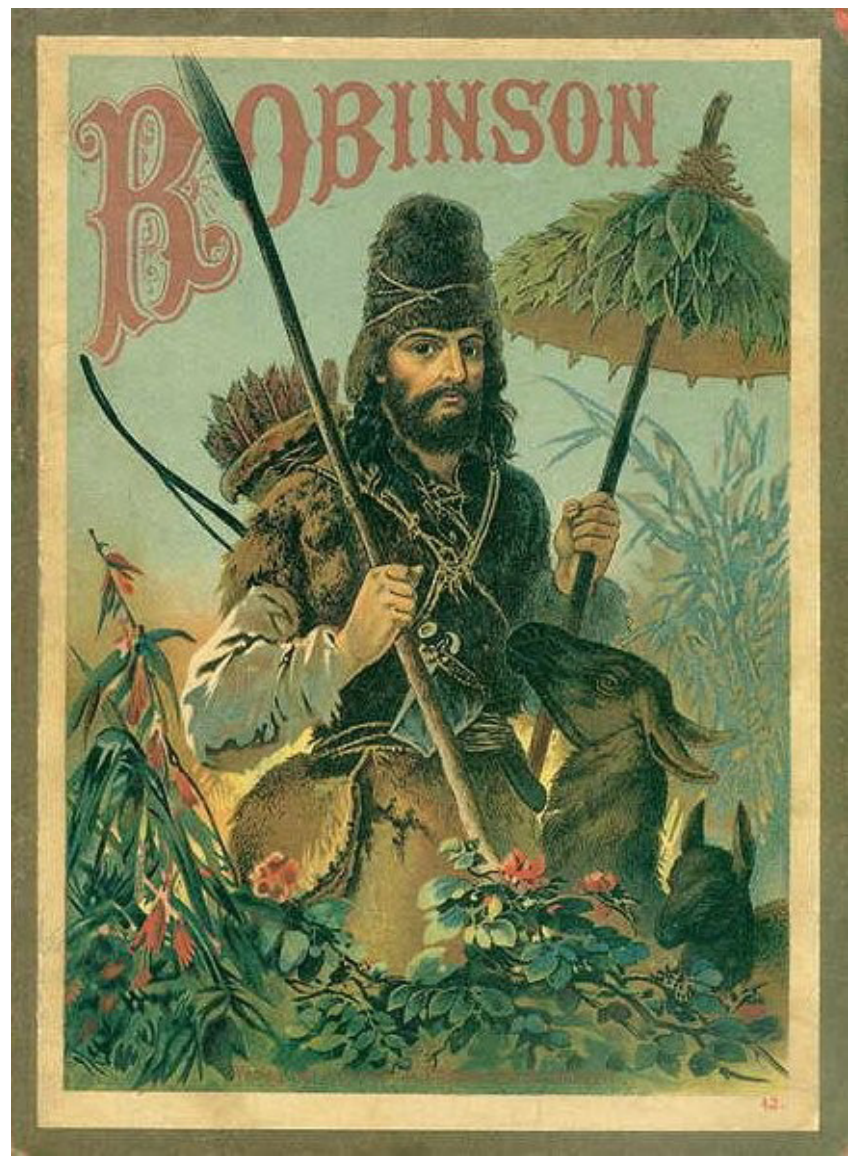

Figura 2: Ilustração de Robinson Crusoé. O barco do náufrago é um sistema fechado que se abre ao campo de possibilidades da ilha que, por sua vez, apresenta-se, de inicio como sistema aberto e depois de explorada se fecha em seus próprios limites e limitaçóes.

Fonte: Wikimedia Commons. Capa da novela Robinson de Joachim Heinrich Campe a partir de aquarela de Carl Offterdinger. 8a edição. Stuttgart e Leipzig, publicado por Wilhelm Effenberger (Verlag de F. Loewe). (ca 1889). A primeira edição foi publicada em 1887.

Hélio Oiticica concebeu seu Éden na Whitechapel Gallery em Londres em 1969 como um "campus experimental [...] uma espécie de taba, onde todas as experiências humanas são permitidas - humano enquanto possibilidade da espécie humana. É uma espécie de lugar mítico para as sensaçóes, para as açóes, para a feitura de coisas e construção do cosmos interior de cada um - por isso proposiçôes "abertas" e até mesmo materiais brutos e crus para "fazer coisas" que o participador será capaz de realizar." (apud FAVARETTO, 2000).

Oiticica afirmava, então: "Meus novos trabalhos são bem abertos [...] Considero-os como trabalhos "abertos" e "cósmicos" [...] (o) que internamente requer uma transformação ou uma identificação daqueles que querem penetrá-1(o), mas esta transformação não seria preordenada: "seja isto" ou "aquilo", não [...].” (BRETT, 1996)

\section{Hibridismos}

A plena potência de concepção de forma - poiesis - que as açóes construtivas encontram no mundo sensível, constituído na interação entre natureza e artifício, como o amplo universo da tékhne, é o paradigma dos sistemas abertos. Os sistemas fechados são, por sua vez, "universos dentre desse universo" (FOCILLON, 1988), subconjuntos dessa totalidade, com limites e potenciais definidos também em razão de uma poiesis, fortuita ou intencional.

Entre os extremos de abertura e fechamento caberiam todas as iniciativas intermediárias, híbridas, mescladas, heterogêneas que, em graus variados, combinam sistemas fechados e abertos em experiências de modelagem diversas.

Iniciativas desse gênero tem como princípio a aceitação tácita da possibilidade de abertura/inclusão. Tais possibilidades intermediárias ou híbridas se constituem, portanto, a partir da extensão e da aplicação da lógica de abertura a ordens mais ou menos fechadas de certos sistemas, e não o contrário.

O movimento e a transformação de uma posição extrema em direção a uma posição intermediária são particularmente difíceis e exigentes quando se parte de sistemas fechados, pois tais alteraçóes habitualmente envolvem: 
- ou uma ruptura de sua lógica, de sua ordem ou do que poderíamos denominar suas normas, e isso ocorre quando um sistema fechado é desintegrado e seus elementos são incorporados em uma outra dinâmica aberta. Por exemplo, quando peças de LEGO são retiradas de um set e tenta-se integrá-las em um processo de modelagem que também considera outras técnicas e materiais;

- ou uma conversão e padronização de materiais, elementos e técnicas externos à sua ordem. Como se um sistema LEGO se abrisse para incorporar peças esculpidas em madeira ou modeladas em cerâmica ou ainda qualquer outro tipo de modelagem que se adequasse à sua modulação e a seus encaixes. A entrada de objetos exóticos em um sistema fechado exige uma conversão à sua ordem. Em outras palavras, para que um sistema fechado preserve sua ordem, suas eventuais aberturas são retroativas: o sistema se abre, converte um elemento externo e volta a se fechar em seguida.

No sentido contrário, quando se parte de sistemas abertos, de um campo de possibilidades e da intenção de experimentação e inclusão, a incorporação eventual de peças ou partes de sistemas fechados é "natural" a essa ordem, constitui e conduz suas dinâmicas inclusivas.

As rupturas, os deslocamentos, os reposicionamentos e as deformaçóes - no sentido bachelardiano (2001) de tais poiesis - se aplicam e alteram, assim, a condição original dos elementos que são apropriados, especialmente daqueles oriundos de sistemas fechados. É possível dizer que sistemas abertos almejam e dependem de estabelecer interaçôes complementares entre materiais e técnicas diversas, enquanto que os sistemas fechados prescindem de tais interaçóes, pois intencionam interagir, antes de mais nada, com eles mesmos.

Como se pôde perceber, não estão em foco nesta breve reflexão os objetivos práticos de tais sistemas de modelagem tridimensional - abertos ou fechados -, nem suas intençôes de comunicação, nem tampouco seus eventuais papéis ou participaçóes em processos projetuais.

Não se trata de caracterizar nenhum desses sistemas como "melhor" ou "pior" a princípio, afinal tal juízo depende de uma análise comparativa da aplicação de certos sistemas específicos a determinadas circunstâncias particulares, o que não está em pauta aqui. Daí se pode inferir que também não está em questão a eventual superioridade técnica ou estética de um ou de outro sistema.

O que se pretende aqui é refletir, em termos teóricos, sobre as naturezas específicas de tais sistemas e as implicaçóes de tais especificidades na potência poética dos sistemas construtivos, ou seja, na capacidade de um determinado sistema em promover passagens entre o "não ser" e o "ser" (PLATÃO, 2011). Para tanto, o enfoque proposto se concentra sobre as diferenças principais entre modos "abertos" e "fechados" de operar sobre a matéria.

Sendo assim, vale prosseguir com a reflexão iniciada no âmbito da modelagem tridimensional para o universo do desenho.

A ação de desenhar também, por sua vez, tanto pode ser uma atividade aberta - se tiver como ponto de partida o intuito de incorporar técnicas e materiais diversos em sua lógica operativa -, quanto pode se constituir como uma atividade fechada, restrita à ordem de um conjunto pré-definido de normas, materiais e técnicas. 
De um lado haveria, então, um campo experimental de açóes gráficas potencialmente abertas, convergentes e inclusivas, e de outro lado haveria açôes de desenho fechadas, excludentes, circunscritas em um determinado sistema espacial integrado de "açóes e objetos" indissociáveis (SANTOS, 2008), com seus elementos, seus instrumentos, suas possibilidades e limitaçôes. Assim como visto para a modelagem tridimensional, entre as duas extremidades de sistemas abertos e fechados, inúmeras variações intermediárias podem ser constituídas.

O desenho técnico executivo de arquitetura, normatizado, "normografado" e grafado a nanquim sobre papel vegetal exemplificaria uma condição extrema de sistema fechado.

No outro extremo estaria, por exemplo, o exercício exploratório do desenhar valendo-se de materiais diversos - grafite, carvão, giz, lápis de cor, etc -, técnicas diversas - dos traçados lineares, aos campos de cor, passando tanto pelo acréscimo quanto pela retirada de materiais - sobre diferentes suportes, dos mais convencionais aos menos óbvios e recorrentes.

A intensificação desse movimento de abertura a experimentaçôes pode levar o desenho a estabelecer interaçóes complementares com outras representaçóes - fora das polaridades do campo do desenhar como sistemas abertos ou fechados - levando-o a atuar sobre tudo o que ofereça uma superfície de desenvolvimento: sobre fotografias, sobre modelos tridimensionais, sobre projeçôes em vídeo, articulando-se a textos, em uma ampla gama de intersecçóes que ressignificariam tanto o desenho, quanto também as outras representaçôes com as quais viesse a interagir. Atuando, para além das representaçóes, a abertura total do desenhar não encontra limites no mundo e transforma a si mesmo e tudo mais ao seu redor.

Essas consideraçóes introdutórias apresentaram, em linhas gerais, aspectos relativos à natureza, aos poten-

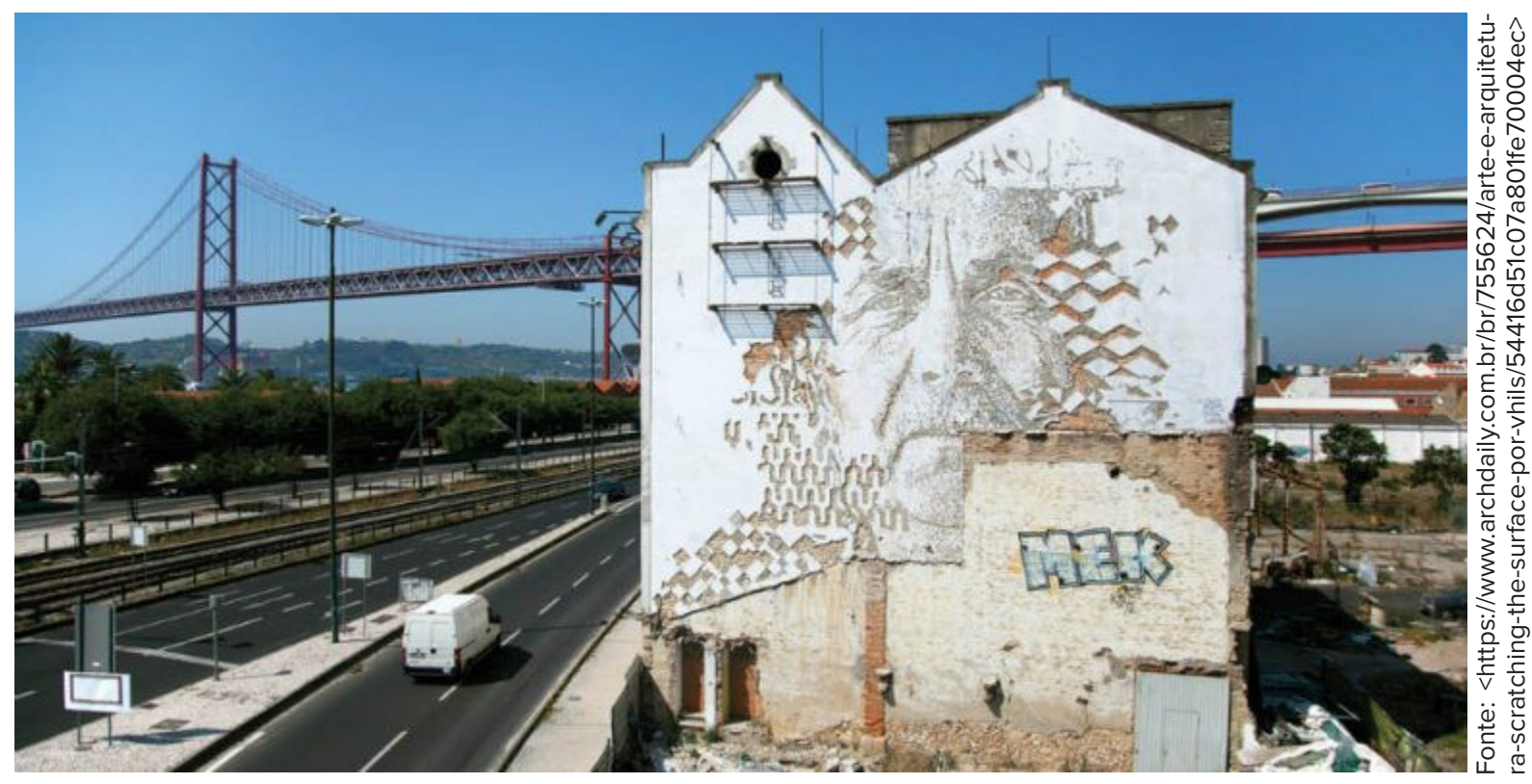

Figura 3: Obra integrante da exposição "Dissecção" do artista lisboeta Vhils (Alexandre Farto) na Avenida da Índia, Alcântara, Lisboa. O grafite e as expressóes de arte mural ressignificam o entendimento do alcance do desenho ao promovem um reencontro contemporâneo da atividade de desenhar com a superfície das paredes e empenas urbanas. 
ciais/limitaçôes, e às interaçôes complementares das representaçôes caracterizadas como sistemas abertos e fechados, tomando como exemplo a modelagem tridimensional e o desenho.

Em termos metodológicos, tais critérios são fundamentais para sistematizar o estudo analítico-crítico das representaçóes no âmbito da Arquitetura, do Urbanismo e do Design que, aliás, carece de maior rigor epistemológico e de perspectiva histórica.

A pesquisa e a indispensável construção de conhecimento sobre as representaçôes demandam hoje, para além de uma tradicional abordagem dedicada às especificidades de cada meio, abordagens e investigaçóes que considerem, sobretudo, o estudo das possíveis interaçôes complementares entre representaçôes, delineando enfoques que contemplem a pluralidade de recursos representacionais e a dialética própria do trabalho de arquitetos, urbanistas, designers e outros projetistas que pretendem interferir na realidade concreta do mundo.

\section{$\mathrm{O}$ digital construído à máo}

O convite da revista PRUMO para uma reflexão sobre o tema "Perspectivas - A Representação em Arquitetura" sugere como pontos de partida a referência do desenho, as transformações decorrentes da introdução de recursos computacionais na representação da Arquitetura nas últimas décadas e a seguinte formulação para incitar posicionamentos: "para muitos e principalmente na academia, o desenho projetivo à mão todavia ocupa lugar de destaque na capacitação de novos arquitetos e ainda é acreditado como o principal recurso para a criação de um projeto.”

Considerando o exposto, colocam-se aqui algumas indagaçôes: quando foi que deixamos de desenhar à mão? E quando foi que começamos a desenhar com instrumentos e/ou máquinas?

A manipulação ou manuseio de instrumentos de desenho é o ponto comum entre os mais antigos desenhos feitos pelo homem (c. 538.000 anos atrás ${ }^{2}$ ), os mais antigos desenhos de arquitetura (c. 2.125 a.C. ${ }^{3}$ ) e os desenhos de arquitetura mais contemporâneos.

Dentre tais desenhos sensíveis, algum foi feito sem que a mão humana e seu desígnio guiassem um instrumento?

Em cerca de meio milhão de anos de história, o que mudou, fundamentalmente, foi o instrumento e a natureza da superfície de desenho. Mais uma vez deve-se afirmar, com Flávio Motta (1975) e Vilanova Artigas (1986), que a suposta simplicidade dos meios gráficos da forma - "coisa” de lápis e papel não deve confundir, nem reduzir o alcance do desígnio que constitui o desenhar. Afinal, essas mudanças singelas se contrapóem à transformaçáo notável resultante da atividade de desenhar que lentamente, ao longo de milênios, ampliou-se em outras dimensóes simbólicas e constituiu a cultura humana.

O desenhar - como atividade cognitiva que forma ideias - é mais profundo e abrangente na cultura do homo symbolicus do que a historicidade das eventuais configuraçóes técnicas de sistemas fechados ou abertos de desenho.

Se em um tempo remoto era o dedo serpenteando na areia ou imprimindo suas pontas com cores na pedra, depois foi uma ponta de pedra afiada na superfície de uma concha, depois o stylo sobre tabuletas de argila, logo cinzéis sobre pedra, mais tarde a pena, então, a caneta, a nanquim e as lapiseiras, e mais recentemente, o mouse, o teclado e a caneta óptica. Por fim, 
hoje, na mais moderna das telas sensíveis ao toque, o homem deseja voltar a desenhar com o próprio dedo.

Esse dedo humano que designa é o próprio elemento semântico central, metafórico, de sustentação do mundo digital, e a etimologia registra essa sobrevivência das digitais do homem em seus instrumentos de desenho.

Vale lembrar que, com o advento da computação gráfica, o papel tradicional e ativo do instrumento de gravar um baixo-relevo, uma incisáo ou um traço de tinta sobre a superfície se transformou em uma interação codificada que, a partir de uma certa designação "digitada", constrói uma linha análoga em uma tela eletrônica e pode dar "saída" desta informação em impressoras, cortadoras e fresadoras que atuam diretamente na matéria.

Se o uso de instrumentos é indissociável das origens do próprio desenho, o uso de telas e sua integração em máquinas codificadas para a construção de desenhos também requerem uma certa perspectiva histórica.

\section{Máquinas de desenhar}

A "tavoleta" que Filippo Brunelleschi (1377-1446) construiu em Florença em 1415 era um aparato com peças móveis que integrava superfícies reflexivas, como espelhos, e perfuraçóes para fixar a posição do observador e projetar, sobre a visão controlada de uma certa realidade construída, uma imagem dessa realidade desenhada previamente em perspectiva. Seu uso também dependia - e ainda depende ${ }^{4}-$ do domínio de códigos envolvidos na fatura do próprio aparato e em seu uso correto. Trata-se de uma máquina codificada, sem dúvida.
A partir das experiências florentinas, Albrecht Dürer (1471-1528) também registrou em xilogravuras várias máquinas equipadas com telas para que os desenhistas pudessem "ver através" e encontrar apoio em superfícies quadriculadas - horizontais e verticais na construção de imagens de objetos em perspectiva. Se tais gravuras documentam, de fato, o modo de operar do próprio artista e o método que preconizava, o desenho em perspectiva se fez então amparado por máquinas mecânicas.

Assim como - segundo a hipótese e as investigaçóes de David Hockney (2001) -, outros artistas desde Jan Van Eyck (1390-1441) teriam se valido de câmeras lucida ou claras para desenharem em perspectiva sobre imagens projetadas por superfícies reflexivas.

Em termos técnicos, a fotografia pode ser entendida como um desdobramento imaginativo do século XIX, que trouxe um aporte químico às experiências de projeçôes de imagens em câmeras lucida e "obscura”, explorados pela tecnologia do desenho em perspectiva com máquinas, lentes, telas e codificaçóes desde as primeiras décadas do século XIV.

Retomando as conceituações apresentadas no início do texto, tanto o desenho em perspectiva amparado por máquinas e códigos, quanto seu desdobramento experimental moderno como fotografia, constituem-se como sistemas fechados de construção de imagens.

A lógica operativa de ambos impõe uma ordem de dentro para fora e exige a conversão de outras possibilidades de representação à sua natureza, ao seu modo de operar.

Nesse sentido, a fotografia, conforme sua ordem, se apropria de todas as outras representaçóes, convertendo-as a seu código e transformando-as em fotografias: fotografias de desenhos, fotografias de ma- 
quetes, fotografias de projeções de vídeo, fotografias de fotografias etc. Evidencia-se assim uma condição "metá" como representação da representação. Contudo, mesmo sendo um sistema fechado, o potencial de abertura da fotografia foi logo reconhecido e explorado, por exemplo, nas experimentaçôes feitas por artistas ligados às vanguardas do início do século XX, que propuseram interaçóes entre fotografia, desenho, tipografia e impressos pop em colagens e montagens como as de Alexander Rodtchenko (1891-1956), László Moholy-Nagy (1895-1946) e John Heartfield (1891-1968). Como bem formulou Arlindo Machado (1996): "[...] explorar as "possibilidades" de um sistema significante implica precisamente colocar-se um limite, submeter-se à lógica do instrumento, endossar seu projeto industrial, e o que faz um verdadeiro poeta dos meios tecnológicos é justamente subverter a função da máquina, manejá-la na contramão de sua produtividade programada."

\section{Transformaçóes e experiências}

O universo digital também pode ser entendido como um sistema fechado, centrípeto, que sempre que se apropria de elementos externos os converte à sua ordem, aos seus códigos, às suas normas e aos seus modos de operar. Foi justamente tal capacidade centrípeta que promoveu ao longo das últimas décadas a confluência de várias representaçóes para o âmbito digital: do texto à imagem, das notaçóes numéricas à tridimensionalidade, da palavra falada à imagem em movimento.

Há que se reconhecer, entretanto, que, na duração da curta história do digital nas últimas três décadas, houve também um movimento centrífugo como abertura em direção a interaçôes complementares com outros materiais, técnicas e representações externos ao sistema.
Saskia Sassen (2013) formulou assim seu entendimento sobre tais interaçóes: "Parte significativa do que pensamos como ciberespaço recebe profunda inflexão das culturas, práticas materiais e imaginaçôes que ocorrem fora dele. Parte significativa do que pensamos como ciberespaço, embora não tudo, não teria sentido algum se excluíssemos o mundo fora do ciberespaço. Em suma, o espaço digital e a digitalização, portanto, não são condiçôes excludentes que se colocam além do não digital. O espaço digital está embutido nas estruturações mais amplas, sociais, culturais, subjetivas, econômicas e imaginárias da experiência vivida e nos sistemas dentro dos quais existimos e operamos."

Consequentemente, a apropriação das ditas tecnologias - que são mais propriamente técnicas -, em razão das desigualdades socioculturais-espaciais não se dá de forma igualitária, homogênea nem linear. A "sobrevivência" (TYLOR, 1878) conflituosa e as transformaçôes contínuas impostas a uma gama histórica e heterogênea de técnicas presentes nos ambientes urbanos atuais - especialmente nas metrópoles - que sinalizam dinâmicas instáveis no horizonte, a médio ou longo prazo, que podem promover aberturas em sistemas fechados deformando-os em uma direção improvável.

Conforme uma dessas dinâmicas instáveis e imprevisíveis a "tavoleta" na "longa duração" (BRAUDEL, 1992) foi transformada em câmera fotográfica.

Que deformações já não teriam sofrido as representaçôes digitais nesse contexto e nessa dinâmica histórica?

Cabe relembrar também que o esforço inicial no âmbito dos sistemas digitais foi de apropriação e conversão à sua ordem. Foi necessário, antes de mais 
nada, criar interfaces capazes de conceber um "espaço" interno, um cosmos, e trazer para dentro da máquina "açôes e objetos" codificando textos, imagens e outras informaçóes para então, sobre tais elementos codificados, oferecer condiçôes de edição e interação interna, com outras representaçôes também digitais.

Tudo isso como meta, em um sentido ideal pois, na realidade, há que se acrescentar nessa trajetória as habituais incompatibilidades de hardware, software, formatos de arquivos, e outros percalços que persistem e são próprios da tékhne.

Implementada a internalização de representaçôes e aperfeiçoadas as ferramentas de edição - processo que segue em curso de aprimoramento contínuo - teve início um esforço de construção de saídas, seguindo a lógica das primeiras aberturas: os alto-falantes e as impressoras. Daí vieram cortadoras, fresadoras, injetoras, extratoras, que consolidaram aberturas capazes de promover um reencontro da lógica fechada do digital com o leque aberto e abrangente de materiais e técnicas existentes no mundo.

Nesse reencontro propriamente concreto, material, sensível, constituiu-se o campo experimental atual que demanda experimentaçôes e reflexôes críticas para que se possa prosseguir na construção de conhecimento e na formação de futuros quadros de profissionais, docentes e pesquisadores.

Desde fins dos anos 1980, esta capacidade de convergência e conversão do digital foi (mal) compreendida por um viés substitutivo e excludente que supôs - não sem alguma razão - que os sistemas digitais eliminariam os sistemas analógicos, sem nenhum horizonte que contemplasse interaçôes complementares. Curiosamente, tal suposição, simplista e substitutiva, se concentrou sobre o desenho e não se estendeu à modelagem tridimensional, por exemplo.
As práticas levadas adiante nos últimos trinta anos reiteraram, no entanto, que coexistem hoje diferentes tempos técnicos. A heterogeneidade das técnicas se sobrepôs e ainda se sobrepóe à pretensa hegemonia de sistemas fechados digitais ou analógicos.

\section{Experiências na FAUUSP}

O Laboratório de Modelos e Ensaios da FAUUSP (LAME) instalou sua primeira máquina de corte a laser em agosto de 2011, muitos anos depois do desejado pela comunidade de alunos e docentes. Esse intervalo de tempo, por outro lado, foi fundamental para o amadurecimento de um entendimento crítico quanto às interaçôes complementares desejáveis entre recursos de modelagem analógicos e digitais.

A instalação dessa primeira máquina digital e das demais que se seguiram entre 2011 e 2014 em parceria com o FAB LAB SP - fresadoras CNC, impressoras 3D (Fused Deposition Modeling - FDM), cortadora de vinil - em nenhum momento pressupôs a desmontagem e retirada de máquinas mecânicas - serras de fita, serras "tico-tico", serras circulares, furadeiras de bancada, tornos, lixadeiras, e outras -, nem de instrumentos e materiais tradicionais como martelos, goivas, arames, parafusos, etc. Ao contrário, o que se pretendeu foi constituir uma convergência não excludente de recursos analógicos e digitais que configurasse um campo experimental abrangente, capaz de amparar as mais variadas iniciativas de desenvolvimento projetual com base na concepçáo e na construção de modelos físicos.

$\mathrm{Na}$ prática da disciplina optativa interunidades "Matemática, Arquitetura e Design" (MAP2001)5 , por exemplo, graduandos de Arquitetura e Urbanismo, 


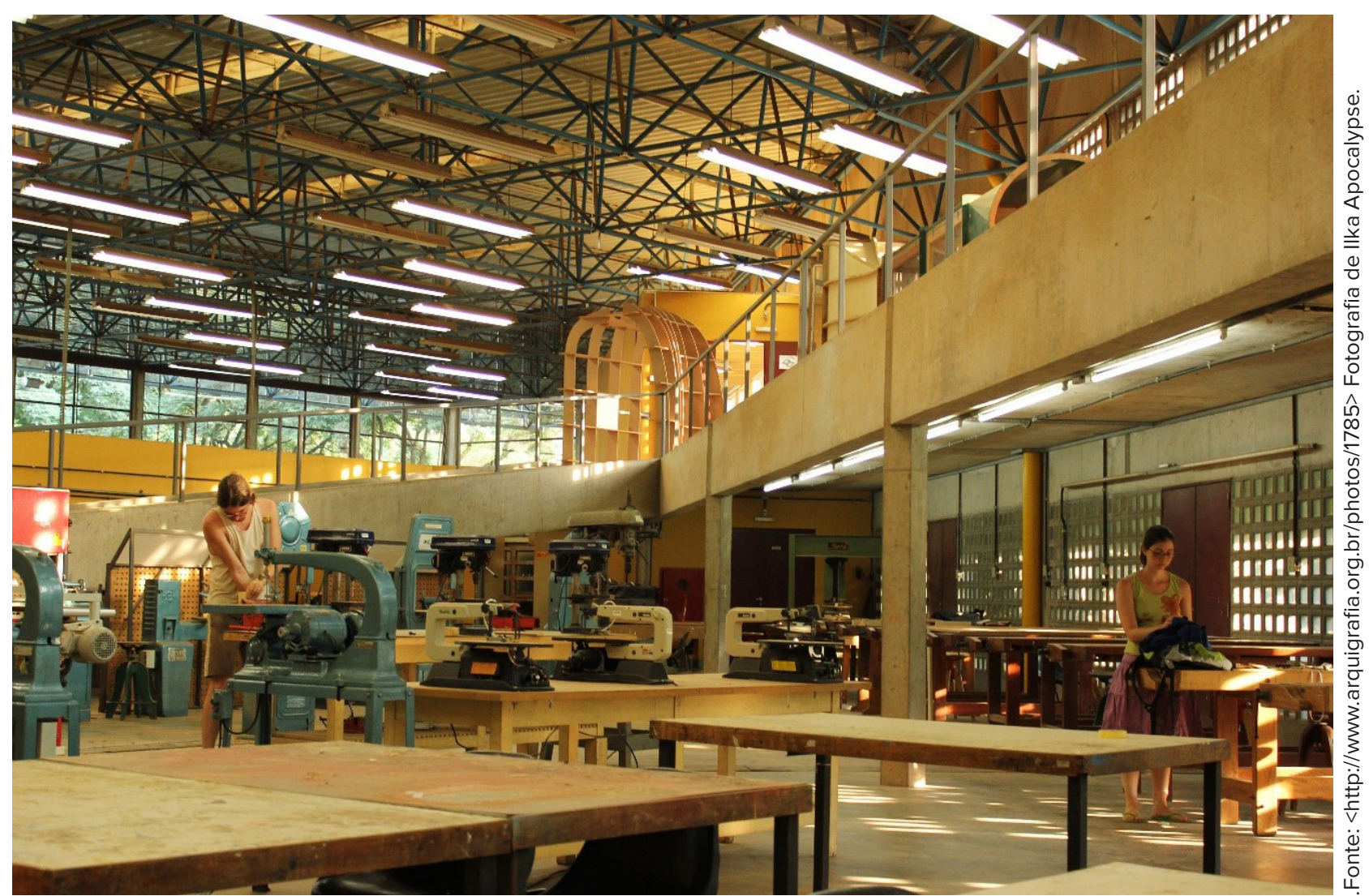

Figura 4: Vista do interior do Laboratório de Modelos e Ensaios LAME, Edifício Anexo, FAUUSP, São Paulo, 2013.

Design, Engenharia, Física, Ciência da Computação, Matemática, e de outros cursos da Universidade de São Paulo, trabalham no LAME em equipes mistas multidisciplinares valendo-se de todos esses recursos disponíveis para o desenvolvimento de seus projetos: da modelagem manual com papéis e papelóes ao corte de peças na laser; da confecção de modelos em gesso à modelagem de peças de madeira maciça na CNC; do corte de chapas de acrílico ao trabalho com argila.

Nas quatro ediçôes dessa disciplina ${ }^{6}$ não houve nenhuma manifestação por parte dos alunos quanto a eventuais conflitos entre o manual, o mecânico e o digital, pois nessa confluência as interaçôes complementares se reafirmaram continuamente como algo positivo, desejado e desafiador. As manifestaçóes críticas que ocorreram - e encontraram eco especialmente entre os alunos que realizam seus Trabalhos Finais de Graduação (TFG) e Trabalhos de Conclusão de Curso (TCC) - diziam respeito à ausência de um ou outro material, instrumento, ou de uma ou outra máquina, o que restringia as possibilidades $\mathrm{da}$ modelagem desejada em um amplo sistema aberto. O laboratório ideal deveria ter a diversidade do próprio mundo.

Nessas práticas, tampouco compareceram conflitos entre o desenho à máo e o desenho amparado por computador. Ambos se fizeram presentes e os processos projetuais configuraram, caso a caso, interaçóes e definiçôes de papéis complementares entre diferentes 
modos de operar, entendendo que o desenho hoje, no âmbito da Arquitetura, do Urbanismo e do Design se faz com o acréscimo dos recursos digitais e não com a supressão das possibilidades manuais.

A afirmação de uma pedagogia do acréscimo, ao invés da supressão, que se enunciou nas práticas do LAME, pode ser reconhecida também quanto à fotografia no laboratório didático da FAUUSP. Muito embora a popularização dos dispositivos fotográficos digitais, especialmente dos smartfones equipados com câmeras, tenha transformado profundamente a prática da fotografia, a diretriz pedagógica que ampara a formaçáo de arquitetos e urbanistas e designers reitera que o aprendizado da fotografia é enriquecido pela experiência com câmeras pinhole, com câmeras analógicas, com a lida com filmes em acetato, e a vivência dos processos químicos de revelação e ampliação de imagens.

Após a apresentação dessas experiências é possível retomar a formulação de interrogaçóes para concluir:

Qual seria a justificativa pedagógica para a supressão de experiências considerando o propósito científico, educacional e formativo que integra ensino, pesquisa e extensão universitária para a formação de futuros profissionais que irão atuar nas mais variadas frentes do "campo ampliado da Arquitetura" (SYKES, 2013)?

Tal aprendizado não traria apenas ganhos à capacidade de apreensão de fenômenos, de representação, de formulação de juízos críticos e de proposição projetual dos futuros arquitetos?

Como o aprendizado prático e o exercício da geometria descritiva e dos fundamentos da geometria aplicada às projeçóes ortogonais, aos desenhos fundamentais da Arquitetura em planta, corte e elevação, e aos desenhos em perspectiva, poderia prejudicar o domínio dos recursos digitais de representação?

Quando toda a experiência do digital compreende e se abre a interaçôes complementares, como defender restriçóes pedagógicas e a alienação do desenho à mão?

Não haveria razóes mais do que suficientes para, ao contrário, defender a intensificação do ensino do desenho em todos os níveis da educação escolar, compreendendo seus sentidos mais profundos como desígnio?

Quais seriam as perspectivas advindas da ampliação e aprofundamento de uma cultura do desenho, aberta a interaçôes complementares entre o analógico e o digital, para o futuro das representaçóes da Arquitetura? 


\section{Notas de fim:}

1. Lévi-Strauss contrapóe bricolagem a projeto, conceituação que se questiona aqui, pois a ação de bricolagem pode ser uma intenção projetual, como é o caso da Nova Babilônia (1959-1974) de Constant Anton Nieuwenhuys (1920-2005), dentre outros exemplos possíveis, especialmente quanto às iniciativas da arquitetura contemporânea após os anos 1960.

2. <https://www.smithsonianmag.com/science-nature/ oldest-engraving-shell-tools-zigzags-art-java-indonesiahumans-180953522/>.

3. Considerou-se para essa datação o desenho em planta na estátua de Gudea, conhecida como "O Arquiteto e o Plano", hoje no Museu do Louvre.

4. Para verificar empiricamente esse nível de codificação da "tavoleta" basta sugerir a alguém que não tenha referência nenhuma desse aparato que o opere, sem recorrer a nenhum manual de instruçóes. Em um nível ainda mais profundo, basta tentar construir hoje o aparato para reconhecer a codificação do objeto.

5. A experiência das três primeiras ediçóes desta disciplina foram publicadas e estão disponíveis no link: <https:// www.blucher.com.br/livro/detalhes/matematicaarquitetura-e-design-1258/arquitetura-149>.

6. Realizadas em parceria com os professores Eduardo Colli e Deborah Raphael do Instituto de Matemática e Estatística da Universidade de São Paulo (IMEUSP), sempre com a participação ativa do corpo técnico de funcionários do LAME, sob a chefia do Sr. Emílio Leocádio.

\section{Referências Bibliográficas:}

ARTIGAS, João Batista Vilanova. $\mathrm{O}$ desenho. In: Caminhos da Arquitetura. São Paulo: Pini, Fundação Vilanova Artigas, 1986.

BACHELARD, Gaston. O Ar e os Sonhos: ensaio sobre a imaginação do movimento. São Paulo: Martins Fontes, 2001.

BRAUDEL, Fernand. Escritos sobre a história. São Paulo: Perspectiva, 1992.

BRETT, Guy et all. Hélio Oiticica. Rio de Janeiro: Prefeitura do Rio, RIOARTE, 1996.

FAVARETTO, Celso. A invenção de Hélio Oiticica. São Paulo: EDUSP, 2000.

FOCILLON, Henri. A vida das formas. Lisboa: Ediçōes 70, 1988.

HOCKNEY, David. O conhecimento secreto: redescobrindo a técnica dos grandes mestres. São Paulo: Cosac \& Naify, 2001.

LÉVI-STRAUSS, Claude. La pensée sauvage. Paris: Plon, 1962.

MACHADO, Arlindo. Máquina e Imaginário. São Paulo: EDUSP, 1996.

MOTTA, Flávio L. Desenho e emancipação. São Paulo: GFAU, 1975.

PLATÁO. O Banquete. Porto Alegre: L\&PM, 2011.

SANTOS, Milton. Técnica, Espaço, Tempo: Globalização e Meio Técnico-científico-informacional. São Paulo: Edusp, 2008.

SASSEN, Saskia. In: SYKES, A. Krista (Org.). O campo ampliado da arquitetura: antologia teórica 1993-2009. São Paulo: Cosac Naify, 2013.

SYKES, A. Krista (Org.). O campo ampliado da arquitetura: antologia teórica 1993-2009. São Paulo: Cosac Naify, 2013.

TYLOR, Edward Burnett. La civilisation primitive. Paris: C. Reinwald, 1878. 